Code of Practice: Mental Health Act 1983 (1990). London: HMSO.

COOPER, S.-A. \& HARPER, R. (1992) Section 5(2): Who acts as the consultant's nominated deputy? Psychiatric Bulletin, 16, 759-761.
Joyce, J. P., Morris, M. B. \& Palia, S. S. (1991) Section 5(2) Audit. Psychiatric Bulletin, 15, 224-225.

Pourgourides, C., Prasher, V. P. \& Oyebode, F. (1992) Use of Section $5(2)$ in clinical practice. Psychiatric Bulletin, 16, 14-16.

\title{
Too high a hurdle? The use of pre-assessment questionnaires in psychotherapy
}

\author{
TERri Eynon, Registrar in Psychotherapy; and StePhen Gladwell, Consultant \\ Psychotherapist, Uffculme Clinic, Moseley, Birmingham B13 8QD
}

Up to one third of patients referred for psychotherapy fail to attend for their first appointment (O'Loughlin, 1990). Psychotherapy assessments are usually allocated a considerable portion of uninterrupted time, and an unexpected non-attendance wastes significant clinical resources. A variety of strategies have been used to ensure that assessors are not left waiting for a patient who never comes. One method is to send out forms which must be completed and returned before a first appointment date is given. In O'Loughlin's study, in which a similar questionnaire to that detailed in this paper was used, it was suggested that sending a preappointment questionnaire reduced the default rate.

\section{The study}

This audit study arose out of a discussion among the staff in a clinic where one team (team A) used a mandatory pre-assessment questionnaire and another (team B) did not. The use of a questionnaire can delay sending out the appointment if patients are slow in returning them and also put extra demands on secretarial staff. With new standards in patient care, any administrative matter which may increase waiting times needs to be clinically justified. This led to a need to re-evaluate the use of questionnaires, and to observe their effect on the numbers of patients failing to attend.

The Uffculme Clinic, the West Midlands Regional Centre for Psychotherapy, takes referrals from primary care and from psychiatric clinics. Personal referrals are usually seen by the named consultant or one of their team, with the larger number of general clinic referrals being allocated to the teams according to their workload.

In team $A$, on receiving the referral, the patient is sent a questionnaire and asked to return it completed in 21 days. The patient is then allocated to one of the team members, and an appointment sent out. The patient is asked to confirm that they will attend by returning an acceptance card within 14 days. In team $B$, referred patients are sent an appointment and asked to confirm as above within 21 days.

The questionnaire is based upon one used at the Tavistock Clinic. The questions are designed to encourage the patient to think about their difficulties and how they relate to their earlier life and current circumstances. They may also indicate the person's motivation to work psychodynamically, and may help in the process of allocating patients to trainee assessors.

Clinic computer records and original files for all patients referred (total 695) to the clinic in 1991 were obtained, and data concerning the two teams were analysed. Failure to attend and outcome at assessment were used to determine whether or not the use of the questionnaire was beneficial in reducing the "waste" of new patient assessment time.

Patients may fail to attend their appointments in a number of ways, and this was coded as follows:

DNRQ = did not return questionnaire (team A only) ANC = appointment not confirmed $\mathrm{CBP}=$ cancelled by patient

DNA = did not attend on the day of appointment (having previously confirmed that they would attend). 
TABLE 1

Attendances for the two teams

\begin{tabular}{lccll}
\hline & Attended & $\begin{array}{c}\text { DNA on } \\
\text { the day }\end{array}$ & $\begin{array}{l}\text { DNA other } \\
\text { (DNRQ) }\end{array}$ & Total \\
\hline Team A & 120 & 11 & $67(54)$ & 198 \\
Team B & 172 & 31 & $20(\mathrm{~N} / \mathrm{A})$ & 223 \\
Total & 292 & 42 & $87(54)$ & 421 \\
\hline
\end{tabular}

Following the example of O'Loughlin, those patients who gave some indication of their intention not to attend were grouped together, as this allows some possibility of filling the vacant slots. The non-attenders were thus put into two groups; "DNA on the day" (the same as DNA in the above coding), and "DNA other" (ANC, CBP and DNRQ). Patients who did attend were coded as follows:

ATR $=$ accepted for treatment

NSA $=$ not suitable at assessment

\section{Findings}

Team B accepted more referrals than team A, as during the study year there were more trainee assessors in that team. Of the patients referred to team A (questionnaire used), 5.6\% failed to attend on the day, with the figure being $13.9 \%$ for team B (questionnaire not used). Figures for attendances for the two teams are shown in Table $I$.

The team using the pre-assessment questionnaire had significantly fewer patients who failed to attend on the day, both as a proportion of the total number of non-attenders $\left(\chi^{2}\right.$ test, $\left.P<0.001\right)$ and as a proportion of the total number of referrals $(P<0.01)$. This team also had a significantly larger number of patients referred who did not attend for assessment for whatever reason $(P<0.001)$.

Of those patients seen by each team the proportions considered unsuitable for psychotherapy were $11 \%$ in team $A$ and $22 \%$ in team B. The figures for acceptance for treatment are shown in Table II.

\section{Comments}

Audit studies allow clinicians to examine their own practice with a view to making improvements in patient care (Feldman, 1992; Parry, 1992). They are retrospective uncontrolled observations, which are able to compare the outcomes of different management. Because they are neither randomised, nor controlled, nor blind it is possible that differences in outcome may be due to factors other than those being compared. The results of such studies assist
TABLE II

Acceptance for treatment

\begin{tabular}{lccc}
\hline & $\begin{array}{c}\text { Accepted } \\
\text { for treatment }\end{array}$ & $\begin{array}{c}\text { Not suitable } \\
\text { for treatment }\end{array}$ & Total \\
\hline Team A & 107 & 13 & 120 \\
Team B & 135 & 37 & 172 \\
\hline
\end{tabular}

routine clinical audit by proposing changes in current practice which are then evaluated, thus closing the audit loop.

This study suggests that the use of pre-assessment questionnaires reduces the number of wasted assessment sessions by reducing the number of patients who fail to attend on the day. However, there is also an increase in the total number of patients who do not attend for assessment, and the potential for lengthening the waiting time.

What should be "best practice" in this case depends on the point of view. If short waiting times and a high throughput of assessments, regardless of patient suitability, are the main criteria for funding, then pre-assessment questionnaires are not in our best interests. If, however, the scarce resource of NHS psychotherapy has to be rationed, then a questionnaire has a place in managing referrals.

Patients cannot have psychotherapy imposed upon them, and can only be treated when they are ready, not when we or the referrer believe or wish them to be so. Some patients seem to delay their assessment by means of the questionnaire and perhaps we should respect their part in the referral process by not considering the referral complete until the patient has, in effect, referred himself.

Questionnaires are not merely a hurdle for patients to jump, but provide a great deal of information about the patient and their difficulties. They can be useful in organising work and selecting an appropriate mix of cases for teaching junior staff. In psychotherapy, patients may disclose material in a questionnaire which they might not disclose when face to face with an interviewer. This may lead to greater awareness of potential problems such as aggressiveness and poor impulse control.

The length of the queue for assessment is more likely to be a function of available appointments than the time taken to return a questionnaire. Using the latter has advantages both as a method of assessing motivation for therapy and effective management of the waiting list. A disadvantage may be the way in which it appears to discourage a large number of patients. Psychotherapy has been accused of being biased towards the less deprived (Holmes \& Lindley, 1989), and it might be that we are making the hurdle too high. 


\section{Acknowledgement}

We would like to acknowledge the help of Mrs $\mathrm{Di}$ Symons, Quality Assurance Nurse, without whose computer skills this study would not have been possible.

\section{References}

Feldman, M. M. (1992) Audit in psychotherapy: the concept of Kaizen. Psychiatric Bulletin, 16, 334-336.

Holmes, J. \& Lindley, R. (1989) The unjust distribution of psychotherapy. In The Values of Psychotherapy, pp. 68-94. Oxford: Oxford University Press.

O'Loughin, S. (1990) The effect of a pre-appointment questionnaire on clinical psychologist attendance rates. British Journal of Medical Psychology, 63, 5-9.

PARRY, (1992) Improving psychotherapy services: applications of research, audit and evaluation. British Journal of Clinical Psychology, 31, 3-19.

( $A$ list of further references and copies of the pre-assessment questionnaire are available from the authors).

\section{Delusions and Hallucinations in Old Age}

\section{Edited by CORNELIUS KATONA and RAYMOND LEVY}

The fascinating but somewhat neglected topic of the alteration in the sense of reality in the elderly mentally ill is tackled by contributors from seven European countries. This book spans the field from the historical and conceptual issues to the latest findings in neuroimaging without overlooking basic phenomenology and treatment. It brings together new clinical data and information hitherto widely scattered in relatively inaccessible publications to provide a comprehensive overview of the topic.

GASKELL Royal College of Psychiatrists

256pp., ISBN 090224147 8, Price £12.50 